\title{
Towards a digital geography of Hispanic Baroque art
}

\author{
Juan Luis Suárez \\ The CulturePlex Lab, University of Western Ontario \\ Fernando Sancho-Caparrini \\ Department of Computer Science and Artificial Intelligence, University of \\ Seville
Elika Ortega, Javier de la Rosa, Natalia Caldas and David Brown The CulturePlex Lab, University of Western Ontario

\begin{abstract}
In this article we propose an approach to the study of art history based on geog-raphy of Hispanic Baroque art by digital means that showcase the multiplicity of possible places of art. Our study advances four elements of a digital geography of art (communities, semantic maps, areas, and flows) - a methodology that can be expanded in future Digital Humanities research.
\end{abstract}

\section{Introduction}

In Toward a Geography of Art, Thomas DaCosta Kaufmann (2004, p. 6) stated that his research would 'investigate how notions of place, of the geographical, have been inflected into writing about change through time, as it has been and is still discussed in art history'. He goes back to some of these ideas in his contribution to the multi-volume catalogue of the 2010-11 international exhibition Painting of the Kingdoms. There he insists on the fact that political geography and artistic geography do not coincide as countries, viceroyalties, native areas, and notions of centre and periphery superpose one another in different research works and cataloguing efforts. DaCosta Kaufmann also emphasizes the need for a theory of diffusion that helps explain the movements of creators, paintings, and features from territory to territory, and the effects these transfers have in the spatial organization of art that experts carry out.
Here, we present the results of a multi-disciplinary collaboration in Digital Humanities, Computer Science and Art History that focuses in proposing a digital geography of Hispanic Baroque art. By digital geography we imply the various possible organizations of the place of art by digital means in a manner that connects various types of data about authors and artworks with different notions of space. This digital geography of art also takes advantage of recent advances in data mining and visualization to offer multiple views of the space of Hispanic Baroque art, as related to geography, movement through territories, transfers over time and cultural borders, clusters of artistic centres (as opposed to centres and peripheries), and movements of works from their places of origin owing to contemporary practices of collection by museums and private collectors.

The results shed light on the different ways in which social practices-from creation to circulation to collection-affect the spatial organization of art 
beyond political territories. The article also shows how culture-defined as information that affects human behaviour (Boyd and Richardson 2005) and represented here by the case of Hispanic Baroque paintings_-organizes different real and symbolic 'places' in different times. We argue that the study of large-scale cultural systems such as the Hispanic Baroque is better understood through a combination of tools and concepts that deal with the complex and evolving nature of the system and can study it through multi-scale techniques that reduce that complexity to a minimum, offering new ways of arranging the space in which that system unfolded over time. Finally, we argue that this methodology can be extended to other projects in Digital Humanities.

\section{Methodology: Data and Visualization}

Over the past few years, we have collected an online BaroqueArt Database (2010) (http://baroqueart.cultureplex.ca/) consisting of $>12,000$ paintings and $>1,500$ creators associated with the territories of the Hispanic Monarchy from the 16th to the beginning of the 19th centuries. The database also contains around 400 series, 200 schools, and 2,500 geographical locations. ${ }^{1}$ On top of the data stored under a traditional entity-relation model, we implemented a system of annotations that would allow to work on the objects stored in the database and provide enough flexibility to describe all aspects of any artwork, thus defining a hierarchy in a structure similar to an ontology. From a set of $>200$ descriptors, we carried out a manual semantic annotation of all artworks (with an average of 5.85 descriptors/ work and peaks of 14 per work). We have taken artworks with six or more descriptors, as we experimentally checked that taking works with fewer than six descriptors would provoke the emergence of a considerably larger number of modularity classes, which would make it even more difficult to draw accurate conclusions from the data. At the same time, the possible mistakes resulting from the manual annotation of the database would have a lesser impact in the analysis as the threshold to filter works by descriptors increases. Measures obtained were as follows in Fig. 1.

To analyze the resulting data set, we represented it as a graph in which artworks are nodes and relations among them are established as a function of the descriptors shared by the works. For example, if an artwork is described through seven descriptors and another work is also using the same set of descriptors, then we say that these artworks are connected through a weighted link of seven. We limited our experiment to the period 1550-1850 and divided the global graph into 12 subgraphs to study the temporal evolution, each of them covering 25 years (Fig. 2).

Then, for each of the periods of our data, we determined the clustering classes that can be considered bags of 'similar artworks', and calculated the distances between classes by measuring the frequency of descriptor usage in the artworks contained in the cluster. We applied our own algorithm to distribute those classes in a $2 \mathrm{D}$ space so that their relative positions represent the relative distances among them (the closer the clusters are, the more similar descriptors they use). We are aware that $100 \%$ accuracy is impossible because of the size of

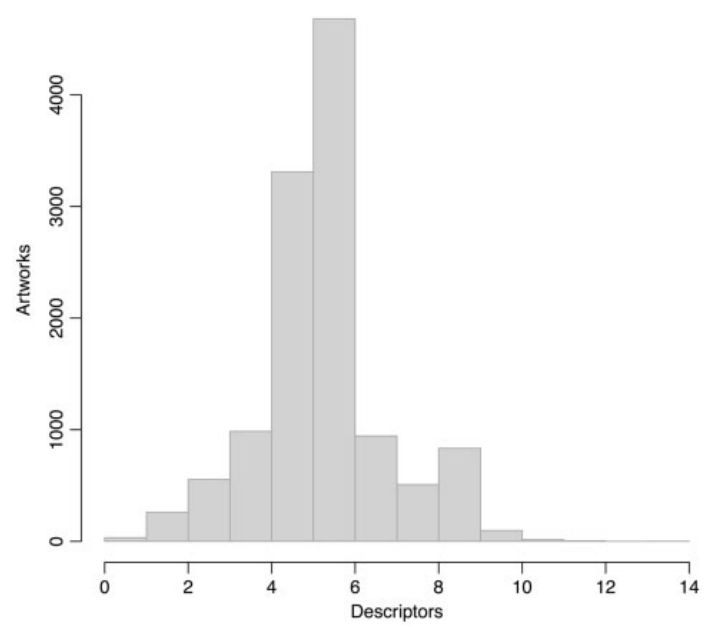

Fig. 1 Descriptors and number of artworks sharing them. Minimum: 1.00, Median: 6.00, Mean: 5.74, Standard Deviation: 1.54, Maximum: 14.00. In the extremes of the distribution: Mean: $\sim 6.30$, Standard Deviation: $\sim 1.00$. 


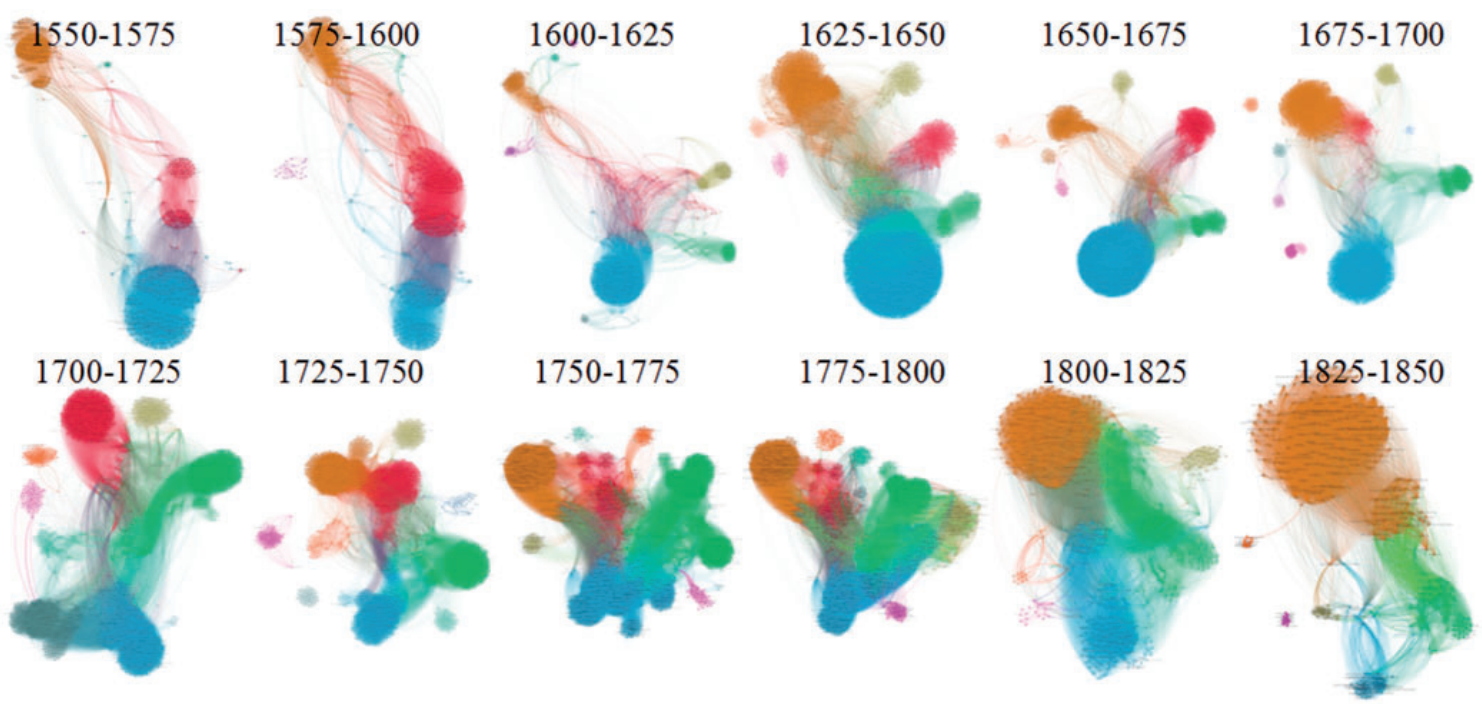

Fig. 2 Graphs showing each one of the 12 periods and the evolution of similarity clusters through three centuries.

the descriptors pool we are using, which would require a higher dimensional space.

Once these clusters are organized in our 2D space with a size proportional to the amount of artworks they have, we went back to the descriptors they contain and we generated the areas of influence of each descriptor as a potential field. As it might be expected, owing to the ontological organization of the descriptors, some of these areas contain other areas or sections within themselves. We also have represented the borderlines of the areas to show how these intersections play out. This allowed us to generate different views of the art-space, taking into account elements such as time, descriptors by modularity class, or specific descriptors closely related to current discussions by art historians specializing in the period (Fig. 3). These different views provide many different facets of Hispanic Baroque art digital geography.

Furthermore, we calculated distances between similarity classes in different periods so that we can infer which class evolved from previous ones and drew the semantic evolution of the artworks. This is fundamental for a better understanding of the generation of families of artworks and the variants that this evolution produces, which would help us connect this process with explanations in political, artistic, or economic discourses.

Finally, and from the geographical information available for a subset of artworks (where original location and current location has been determined), we were able to make a representation of artwork movement along time, and obtain information about how museums (currently the main artwork repositories) and other collectors have accumulated artworks from specific areas or those observed in previous semantic group analysis.

This methodology addressed different issues related to the political, geographic, and cultural aspects of art production, reception, and consumption. Some of these questions are as follows: Are paintings local, regional, or national? How different visualizations affect the clustering of art-works and artists? Are there differences between political and artistic territories? What is the transmission of features across time and space? Which is the effect of flows of artworks away from their place of origin due to market forces? How different clusters of art behave and what is their effect on centre-periphery debates? The result is a digital geography of Hispanic Baroque art that will contribute to a better understanding of art history from a spatial 


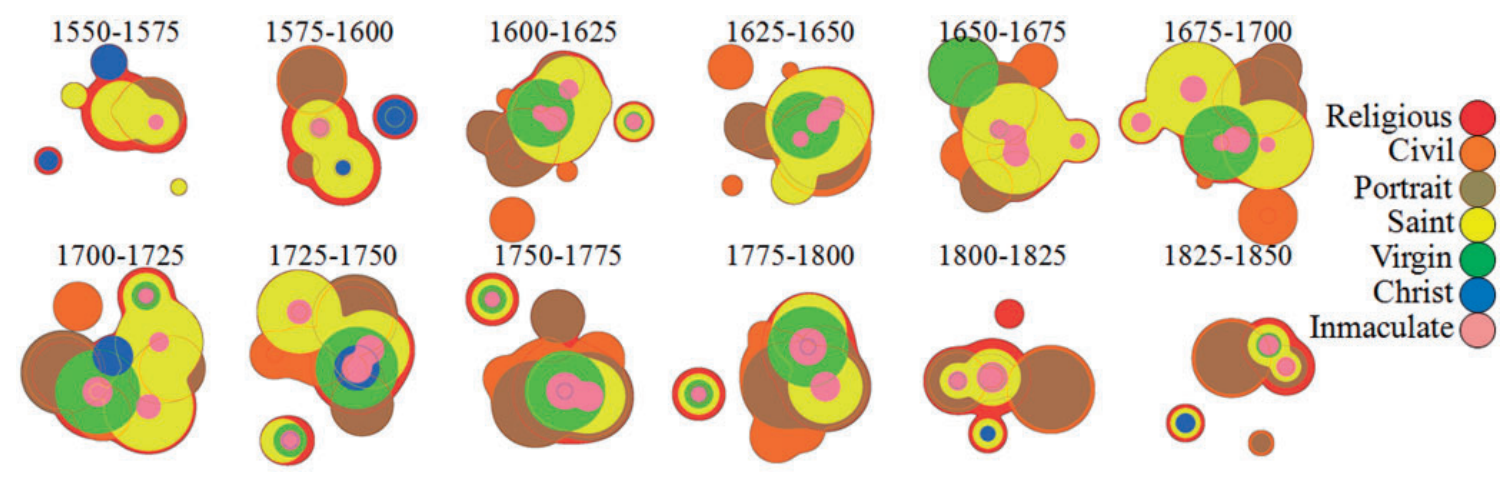

Fig. 3 Twelve art-spaces from the point of view of main descriptors.

point of view and will also shed light on cultural transfers in complex systems.

\section{Elements of a Digital Geography of Art: Communities, Semantic Maps, Areas, and Flows}

Notions of space in art history have been traditionally affected by discourses of nation building, approaches focusing on the physicality of the artwork, the specific spaces for which paintings were commissioned or planned, or by the places in which artists lived and worked. Art history, as it has generally happened in cultural history, has had the tendency to emphasize the study of single works and specific artists - the artist as a collection of all of their works. When dealing with large political structures encompassing many territories or lasting for long periods, as is the case of the Hispanic Monarchy, the traditional approach to the artspace is not as helpful in revealing that 'political and artistic geography do not coincide' (DaCosta Kaufman 2008, p. 99) and that a global vision that takes into account a universal empire that goes beyond the notion of Spain is required.

Here 'global' means three interconnected things. First, it refers to an initial notion of space that is world-wide in its scope, and that might eventually extend to all corners of the world. The possibility of reaching any place in the world does not have to be actualized at every instance of the analysis-simply, there are spaces with no art-but it has to show the mechanisms susceptible to new connection points not considered thus far-a case, an event, an artist, a work - to the existing network of artistic nodes. At the same time, this understanding of a global space of art has to make clear how notions of place are coded into the main network. That is, if we are dealing with 'Portuguese' or 'Christian' painting in Goa, we have to semantically load the edges that will connect those paintings among themselves and the rest of the network with the appropriate notions of geography. Are we going to talk about patterns of artistic diffusion? Are we dealing with centre-periphery relations? Does our interest lie on local interactions and local transformation of exogenous elements? The conclusion is that the possible space is universal, and that this 'universe' has to remain the geographic framework for specific places of art that will emerge through different studies. These places of art are the focus of our interest.

'Global' also means that, at least at this point, there is no predetermined set of valid notions of an art geography that would exhaust all possibilities to find and explore notions of the place of art. Because a geography of art would be connected to specific cultural constructs and theories and, consequently, to various notions of the place of art, there is no categorical hierarchy that would cover them all. In a digital geography of art, we try to overcome this problem both by avoiding the notion of a hierarchy of conceptual categories and by working at the level of the raw data to organize information in terms of graphs. The information about the 
paintings, authors, schools, etc., is semantically tagged through an ontology that can be curated by the researcher as their objectives change from one project to another (Suárez et al 2012). Also, the information is stored and analyzed in a graph structure. A graph is a representation of a set of objects where some pairs of objects (nodes or vertices) are connected by links or edges (Trudeau 1993). This allows for a dynamic process in which notions of the place of art are connected to the specific concepts of each analysis, notions of space as territory, and the possibilities of data analysis and visualization that can be unfolded by mathematical and digital techniques.

Third, 'global' is still to be populated with concepts of cultural theory that helps us understand the 'global' life of art expressions. In the context of this work, the multi-volume catalogue and the exhibition Painting of the Kingdoms ${ }^{2}$ revolves around the idea of the 'shared identities' that can be detected through the large pool of artistic production created throughout the Hispanic Monarchy. For instance, John H. Elliott's chapter is anchored on the notion of the 'kingdoms' and the idea of a composite monarchy in which the total was bigger and different than the sum of its parts. The kingdoms are the 'loci' of his analysis in an effort to show both the diversity and the unity of a complex structure (Suárez et al 2007 and Elliott 2008, p. 46). For Juana Gutiérrez Haces (2008, p.137) the notion of 'koine' is the thread that allows for a better understanding of the history of art in the Hispanic Monarchy. ${ }^{3}$ Her objective is to explain 'how the painter's mentality in the Spanish realms was shaped vis-à-vis a process known as koiné or leveling [...] This process consisted of shedding the unique features of each contributor in favour of what they all shared. The purpose was to create a new language and to foster a sense of belonging to a group, as part of adjusting to a new reality'. Another example of the different ways of looking at the global nature of this type of production is adopted by Helga von Kügelgen, in her systematic study of the way Rubens' influence extended across the kingdoms in what becomes an incredible source to study the patterns of cultural diffusion and imitation with real data in a real case (von Kügelen 2008).
These are just a few examples of what could be a possible geography of art that according to DaCosta Kaufmann (2008, p. 88) 'addresses questions such as how is art related to, determined by, or determines, or is affected by or affects the place in which it is made; how art is identified with people, culture, region, nation, or state, or combinations of these; how art in various places is to be interrelated, through spread, contact, and circulation; and how areas of study are to be defined'. ${ }^{4}$ Given the nature of these problems, we propose that a digital geography of Hispanic Baroque art would positively influence the different ways in which we perceive relations between place and object, and it would shed light on how to arrange those relations through digital means to provide answers to the different issues described above.

A digital geography of Hispanic Baroque art is concerned with the various possible organizations of the place of art by digital means in a manner that connects various types of data about authors and artworks with different notions of space. There are two foundations to this approach. First we adopt Richerson and Boyd's definition of culture as 'information capable of affecting individuals' behaviour that they acquire from other members of their species through teaching, imitation, and other forms of social transmission' (2006, p. 5). By adopting this definition, we are able to deal with information as data that are encoded, that moves and transfers from place to place, and that are cultural information because they affect the behaviour of human individuals in a way that we can trace and model (Suárez et al 2011).

As DaCosta Kaufmann (2008, p. 96) has highlighted for the case of art, views of geographic processes are entangled with the notion of cultural transfer. $^{5}$ It is only by unearthing the networks that allow for information to be transferred among individuals through time and space (McNeill and McNeill 2003; Castells 2009; DiMaggio 2011) that we can rigorously explain how cultural transfers (Goodenough 2002; and DaCosta Kaufman 2008, p. 96) take place, and how they affect artistic production in different settings. Hence, when we talk about cultural transfers we assume that 'mental representations are non-discrete, cultural transmission is highly inaccurate, and 
mental representations are not replicated, but rather reconstructed through an inferential process' (Heinrich and Boyd 2002, p. 87), so that it is likely that cultural transfers do not happen by exact replication. Cultural transmission requires external storage where information is ready to be accessed, decoded, and replicated in different media and contexts, however inexact this replication might be.

In a digital geography of art, the cultural object remains at the centre of all emergent spaces, as these spaces digitally recreate possible arrangements of the place of art-lived spaces in which individuals and groups experience art according to economic needs, pressures that require fostering religious prosociality, or aesthetic pleasure. The cultural object links the author with its audience, known or unknown, and also connects the artwork with the means of cultural transfer. Finally, the various visualizations of those spaces allow for new categorizations of the artistic production and for emergent meanings of art.

The first method of a digital geography of art produces cultural communities as a result of the clusterization and visualization of the data from the Baroque Art Database around modularity classes. One of the more usual forms of graph analysis searches for modularity classes or how a network decomposes into modular communities, or subnetworks with actual meaning in the real world that they represent. These data communities respond to fundamental questions about the formation and maintenance of cultural communities. For Sperber and Hirschfeld (2004, p. 40), a 'cultural group is held together by a constant flow of information, most of which is about local transient circumstances and not transmitted much beyond them [...] Culture refers to this widely distributed information, its representations in people's minds, and its expressions in their behaviors and interactions'. These communities of data resulting from the analysis of the graph show how the flows of information of the paintings from the database get reorganized over time. They also show how these flows give rise to other communities that emerge as the effect of the information shared by the artworks and used by individuals and groups in different contexts.

The fact that we can demonstrate the existence of a constant flow of shared information over a long period leads to the issue of the sustainability of political and cultural communities across time and space. Our analysis of the religious information content carried out within the network of baroque paintings in the Hispanic Monarchy proves that a global community-however fragile-was formed as a result of the European expansion into the Americas and that it was possible thanks to the common religious-Catholic-content carried within the paintings in the network (Suárez et al 2012). The graphs also show that the cultural community was not homogeneous, as the different data communities change their shape and get transformed over time owing to specific artistic, political, and socioeconomic circumstances (Suárez et al 2011).

It is interesting to note that the communities are not necessarily political and that the concept of geographic space does not apply in many of the cases, as it is the change of semantic descriptors over time and the different periods that show how the communities are formed and reorganized according to a multiplicity of factors and the combination of semantic tags that describe the paintings. In this regard, we borrow Gutiérrez de Haces' (2008) concept of 'koiné' or process of leveling in New Spain's painting, and retool it to express the many different processes of leveling that actually take place not only between Spain and New Spain, but also with regions and periods-cultural areas as territorial insertions-in New Spain.

This takes us to the second element of a digital geography of Hispanic Baroque art, that of semantic maps. Semantic maps are strategies to represent the multiple relations of concepts or, in our case, the semantic descriptors that make up the ontology we use to classify the paintings in our data set. They are especially useful when there are many possible relations and also many items to be compared with one another. They also have the advantage of showing the knowledge associated with the descriptors.

By using semantic maps instead of a traditional categorization around genres, we exploited the power of the graph structure, the multitude of connections that paintings have in the real place(s) of art, and the temporality inscribed in the data structure for our artworks. In Graphs, Maps, Trees, 
Franco Moretti (2005, p. 14) explains that genres are 'temporary structures [...] morphological arrangements that last in time, but always only for some time'. However, the problem with genres is that they become closed structures with definite boundaries that end up forcing live works into dead categories. Also, genres tend to become permanent boxes as they encapsulate forms to make them not change over time. However, paintings change over time as a result of cultural transfer, both within the same cultural areas-cultural replication is not exact-and across cultural borders-when local traditions and external forces clash and strive for new synthesis.

To reflect these changes, we propose that a most efficient way to represent the changing descriptors that artworks share is through a semantic organization that includes the features in such a dynamic way that gets the best of an ontology structuring our graph. By using semantic maps, we captured the two dimensions of genres as Moretti refers to them, we represented 'form', but we did it by looking at History, at the changes these forms undergo over time and space.

These changing relationships within the semantic content of our data set are shown in the evolution of the main descriptors that result from our analysis. Of special interest are the relationships between paintings with the descriptor 'religious' and those that are described as 'civil'. Although 'religious' is over time the most abundant descriptor, as it relates to the large majority of works in the data set, we see that as the 18th century advances, the relation is inverted and 'civil' starts to take over in absolute numbers to the point that it becomes the most used descriptor of the database at the beginning of the 19th century. Also noticeable is the constant increase of works related to 'portrait', one of the most understudied themes in Hispanic American painting. Although we have explained in political and historical terms the causes of these variations (Suárez et al 2011a), what we want to highlight is that these relations do not imprison the works into single and exclusive categories. On the contrary, comparison through semantic maps showcases the richness of the information contained in the paintings, the multiple approaches available for its analysis, and the mechanisms by which cultural information gives life to different communities in different or the same cultural areas.

Cultural areas are another important element in the digital geography of art. We define a cultural area as a virtual or concrete space organized through the same information technology and a flow of common culture shared by a population in various degrees. An interesting thing about cultural areas is that once a researcher has collected enough information about a cultural phenomenon, the information itself gets organized in many different ways vis-à-vis the experiences of various groups and even the standpoint of the researcher. This is when DaCosta Kaufmann's statement about the disagreements of the political and artistic geographies comes true, as there are as many geographies of art as cultural areas. Cultural areas are also relevant when dealing with the concept and materiality of cultural transfers. This is especially important in the case of Baroque art. As Llewellyn and Snodin have pointed out (2009, p. 20), 'the Baroque means many different things even across the visual cultures of Western Europe, depending on the date and the character of the work of art under consideration. There is no convincing Baroque Zeitgeist, in the fullest sense, argued by the great cultural historian Jakob Burckhardt, nor does Wölfflin's model of the Baroque-as a reaction against Renaissancealways apply. We present the Baroque as a complex stage in the development of the post-Renaissance classical language of design and we explore it through themes such as assemblage and synthesis, the visual exploration of the physical space, the illusion of movement and naturalistic ornament. Common to nearly all the works of art discussed is that they result from the transmission of people, ideas, motifs or materials'. When we include Hispanic America and Asia to this picture, the Baroque becomes many more things than just an artistic language.

Cultural areas allow for the study of similarities and degrees of difference. As the graphs show, the initial differences and gaps between the artistic production in Spain (blue and dark green clusters), Mexico (purple), and Peru (dark violet) at the beginning of the Baroque period, 1550-1650 (Fig. 4), 


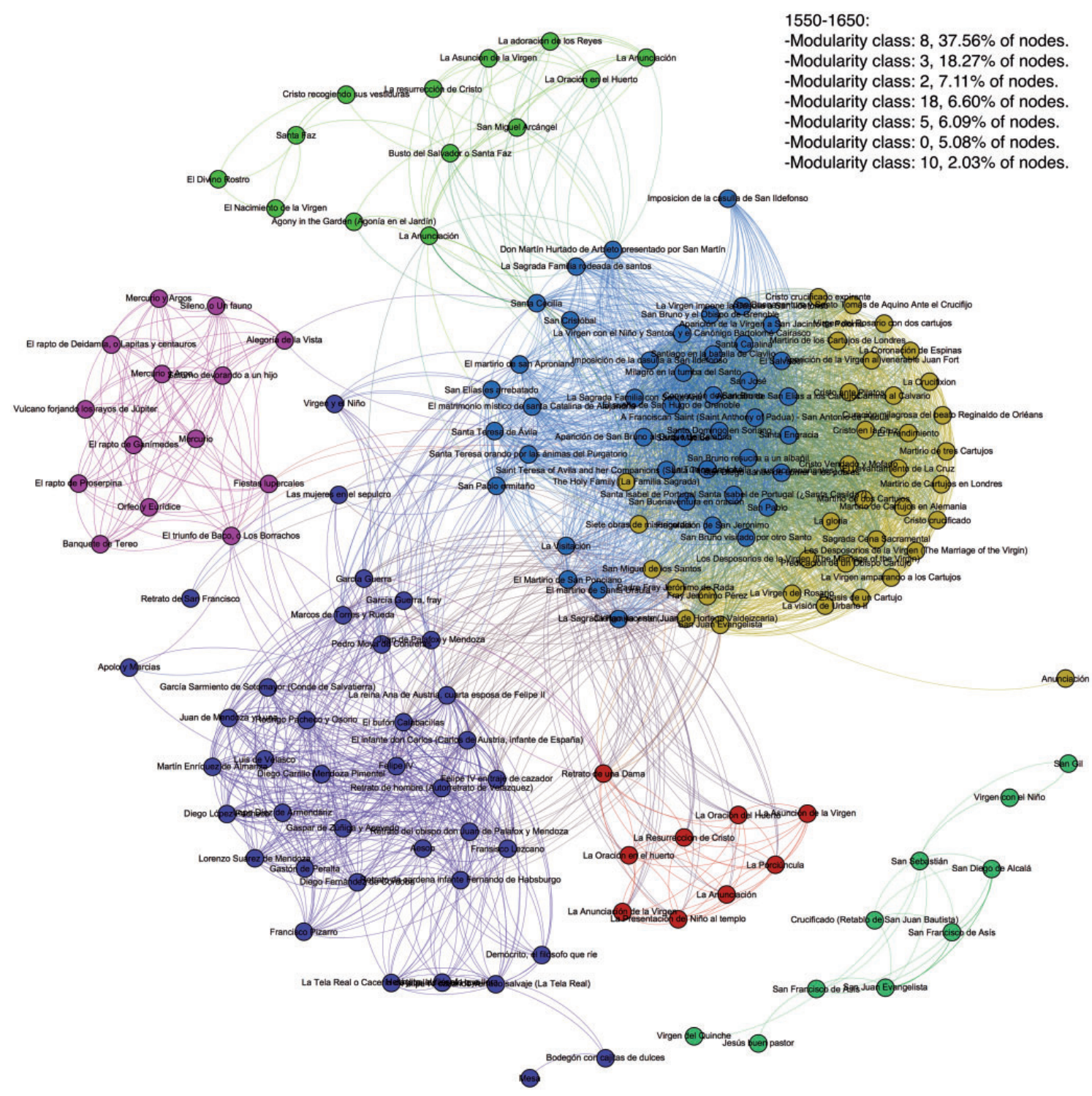

Fig. 4 1550-1650 period.

get transformed in the second period, 1650-1750, thanks to the homogenization caused by the excess of religious content in the artistic information (Fig. 5). As historical and political circumstances related to the independences of Latin American nations affect the production of paintings, we see that the size, number, and composition of clusters change, and that while there are certain types of content shared by all three political entities (Spain,
New Spain, and Peru), others diverge to become relevant only in certain territories, or become related to newly formed cultural areas (Fig. 6). As the political geography changes so does the artistic geography, even with much more detail when analyzed and represented digitally. But the opposite is also true: as we change the focus of the artistic geography, certain concepts of political geography do not hold for this kind of material. 


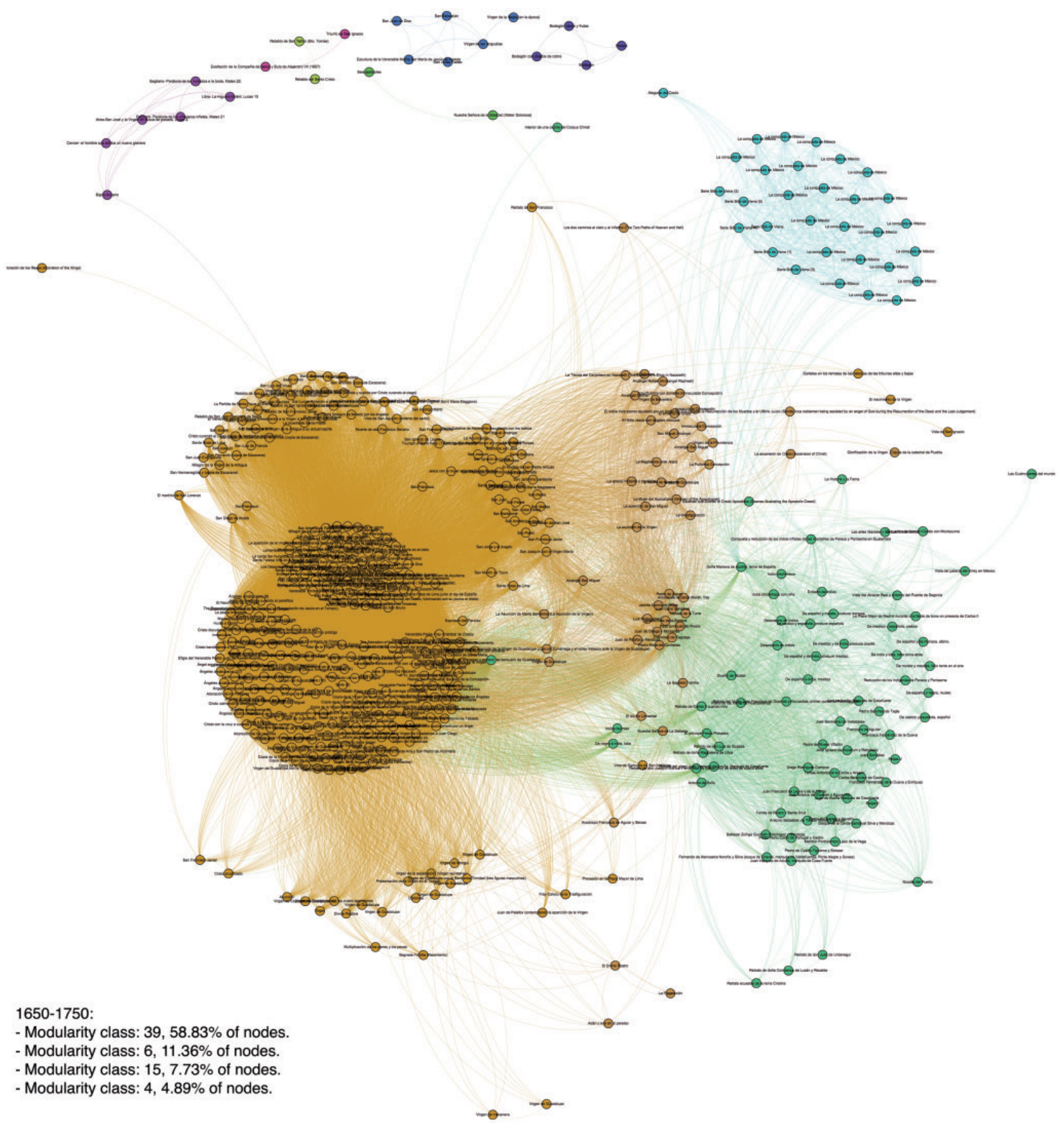

Fig. 5 1650-1750 period.

In cultural areas, we find traces of communicative exchanges, which are also the stage in which cycles of cultural change take place. Cultural areas respond to the mechanisms that Sassen (2006, p. 418) has explained for territorial insertions, which do not necessarily entail subsumption under exclusive state authority because they are predicated on specific denationalization in laws and policy in the service of a global regime. These processes of multi-authorities used by Sassen to describe the current wave of globalization have also been well studied for the case of the first globalization and the Hispanic Monarchy. John H. Elliott's article quoted above 'One King, Many Kingdoms' explains how 
1750-1850:

-Modularity class: $55,32.28 \%$ of nodes.

-Modularity class: $45,23.38 \%$ of nodes.

-Modularity class: $0,18.74 \%$ of nodes.

-Modularity class: $36,9.83 \%$ of nodes.
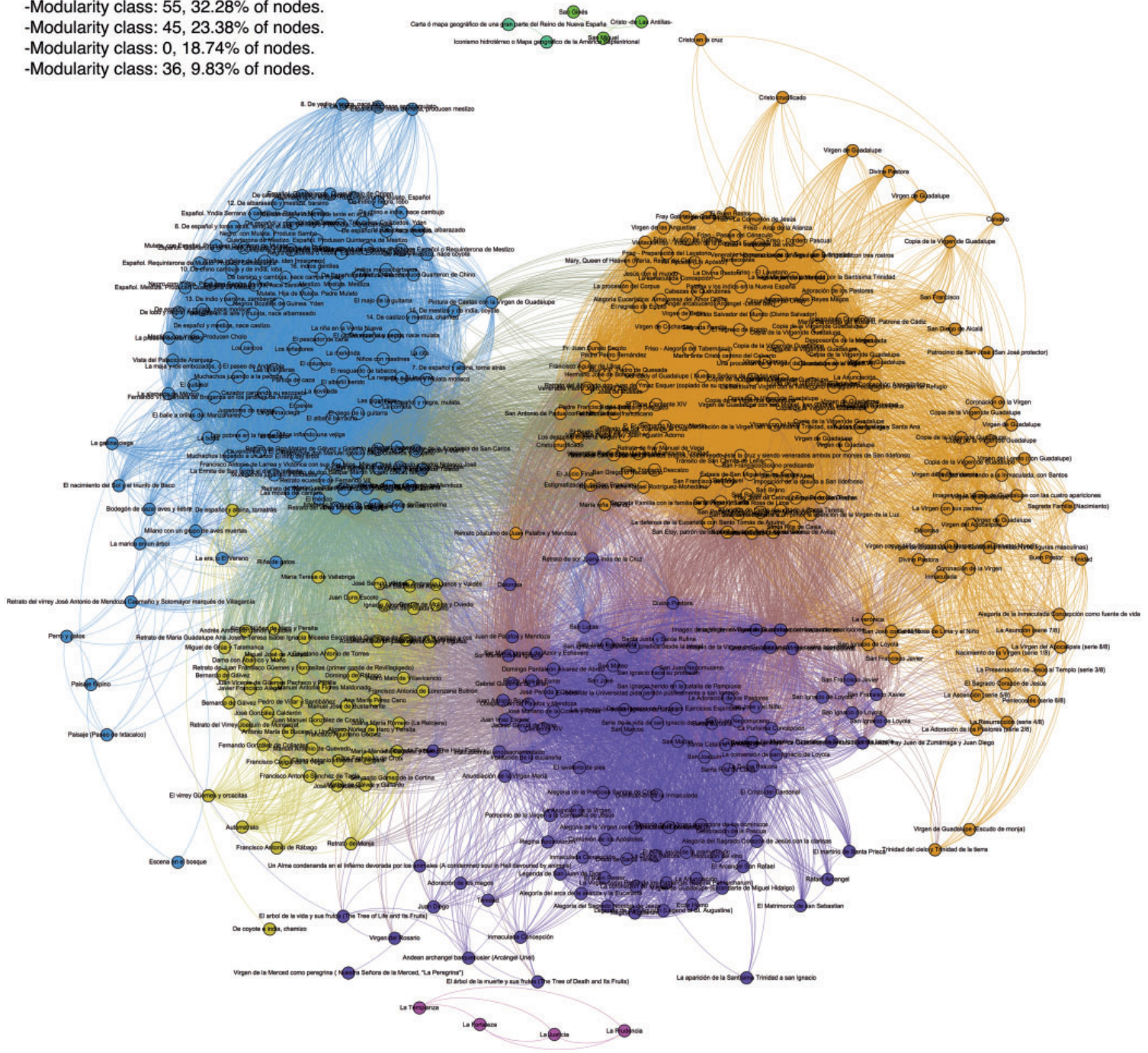

Fig. 6 1750-1850 period.

the political articulation, the legal codes that rule the relations between political entities, and even the traditional customs and allegiances would vary from territory to territory depending on the agreements achieved between the Monarchy and the local elites. The complexity of the political structure is only a reflection of the even more complex weaving and unweaving of culture that results in communities and areas that share common experiences and lived spaces. As Sassen points out (2006, p.3), '[these processes of globalization] are multisided, transboundary networks and formations which can include normative orders; they connect subnational or national processes, institutions and actors, but not necessarily through the formal interstate system'.

One can analyze and visualize the data of the Hispanic Baroque Database through the lens of the histories of the nation states. This is what DaCosta Kaufmann (2004, p. 99) has called the 
national model of art history, one in which the geography of art gets constrained by the political borders of the political entity that serves as the container of the artistic production. When theories of diffusion are combined with the national model, conceptual variants around the 'indigenous' and the 'hybrid' or 'mestizo' show different aspects of the same national production. In these cases, the nation becomes more inclusive. However, we can see that there is much more richness to be explored if we apply the concept of cultural area to regions such as Mexico City (Fig. 7), where the weight that Mexico has in the artistic production of a highly populated area is evident, as well as the links that connect Mexico to Puebla in terms of proximity, rivalry, or themes.

In another case, Oaxaca during the same period of 1750-75 (Fig. 8), we zoomed in the visualization and observed ways in which paintings from Oaxaca could be connected, through geographic means, to Central America and the Andean region as well as their Mexican siblings. There are possibly many cultural areas that, fitting into the definition of lived spaces of art, are not given the same kind of attention, or are wrapped up under the same political or historiographical concepts or standpoints that apply to better established areas.

The internal diversity of cultural areas (DaCosta Kauffman 2004, p. 99) is also an important theme of a digital geography of art. If we connect our cultural areas through the creators, and we search for them throughout the whole territory of the Hispanic Monarchy, we can see that over time there is a great shift in the most important nodes of the artists' network. In the period 1550-1650 (Fig. 9), Vicente Carducho (mainly in Spain), Peter Paul Rubens ${ }^{6}$ (von Kügelen 2008), and the anonymous painters, are the nodes with most connections. In the final period of 1750-1850 (Fig. 10), it is a single Mexican painter, Miguel Cabrera, who gets all the attention and becomes the most influential at both sides of the Atlantic. This begs the question of what a 'Hispanic' history of art around the great influencers and diffusers, such as Rubens and Cabrera, would look like. In the period of 1650-1750 (Fig. 11), a variety $^{7}$ of artists exert their influence around different cultural areas, semantic descriptors, and techniques.

Jonathan Brown (1999) talked about the Hispanic Monarchy as a triptych in which art influences would commence in the Low Countries,

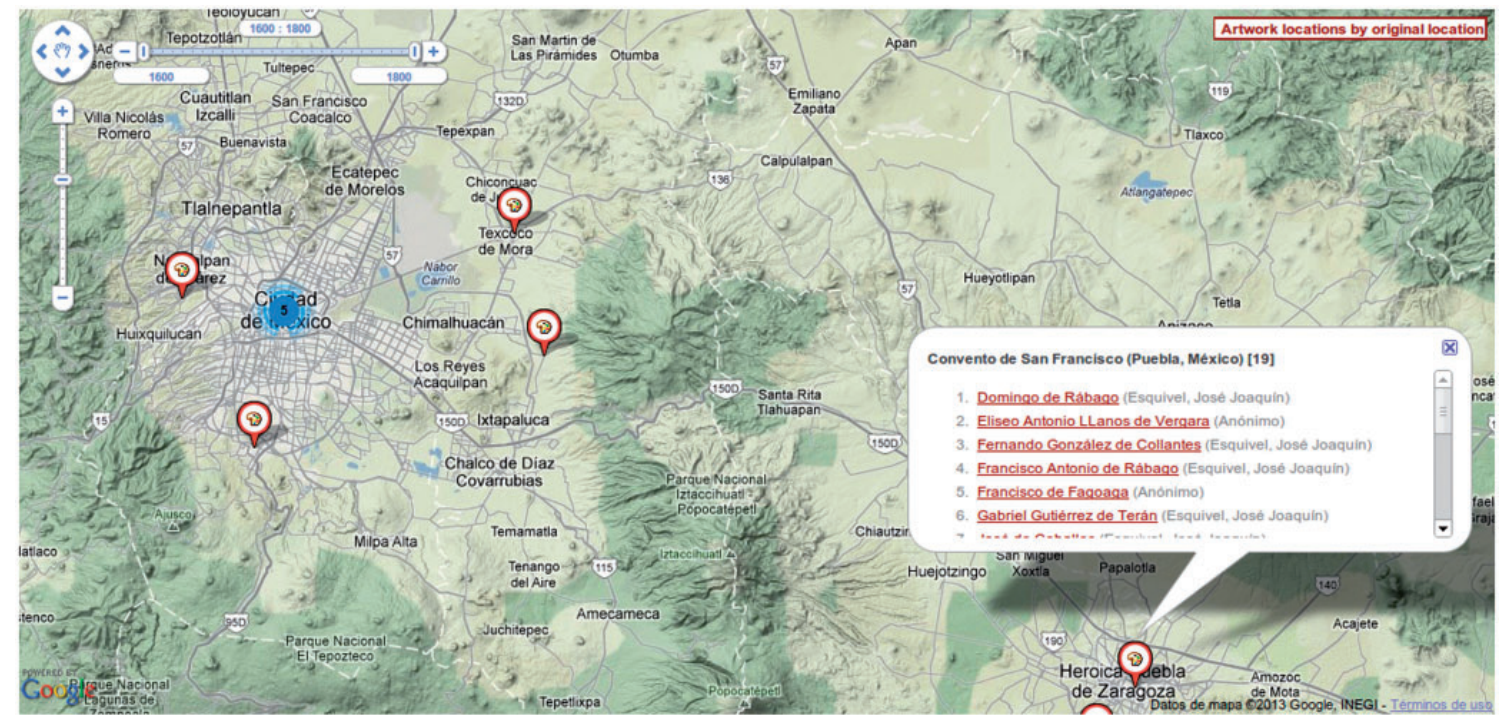

Fig. 7 Mexico as cultural area in 1750-75 in proximity to Puebla as an area of influence. Screenshot generated from the source tool baroqueart.cultureplex.ca. 


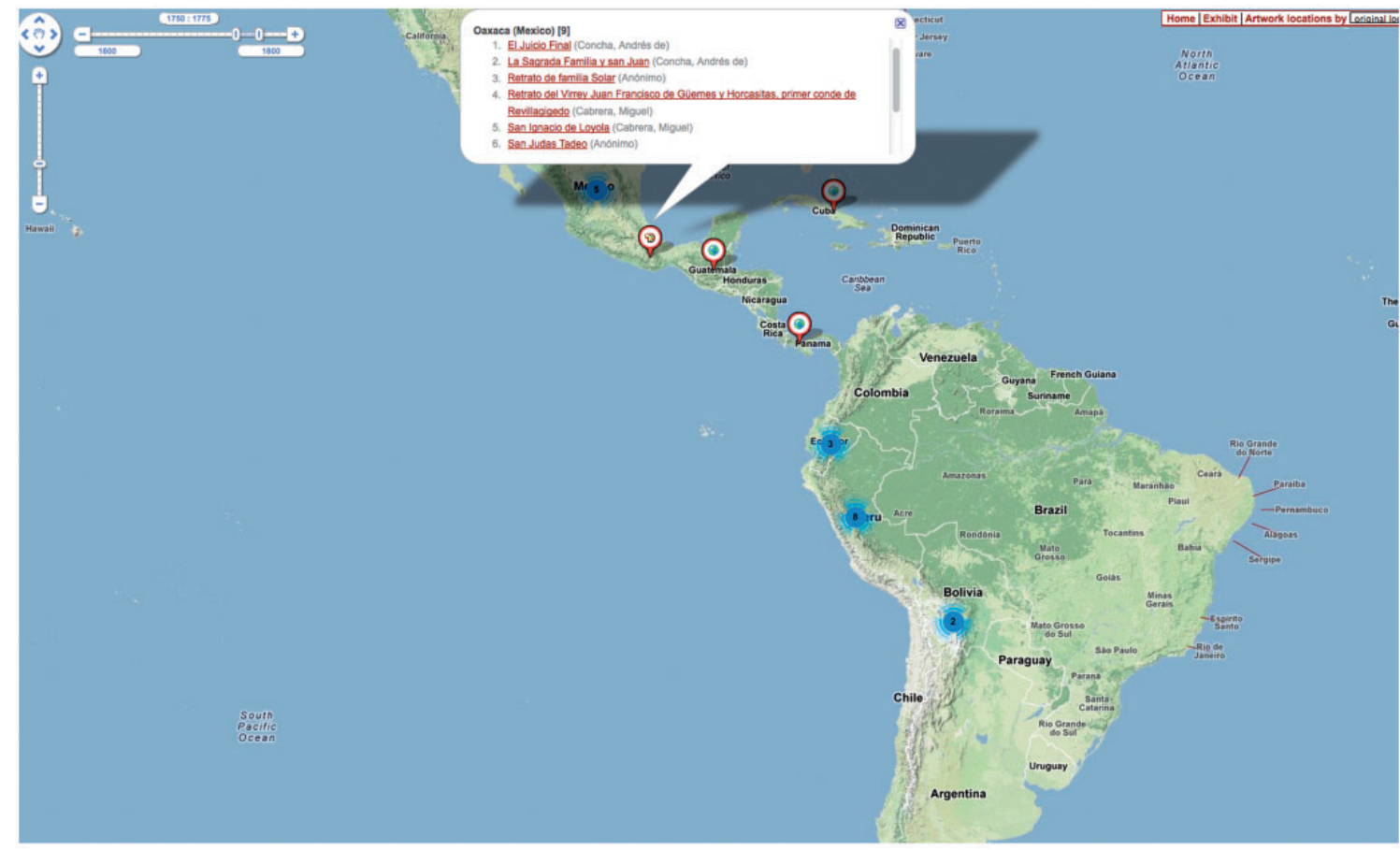

Fig. 8 Oaxaca as a cultural area in the context not only of Mexico, but of Central America and the Andean region 1750-75 through which influence flows. Screenshot generated from the source tool baroqueart.cultureplex.ca.

would move to the Iberian Peninsula, and from there would sail the Atlantic to reach and impact the creation of American art (Fig. 12). On each part of the triptych we would have schools, authors, and local contexts that would interact with the incoming flows of information. Brown's intuition joins a tradition of historiography that has tried the boundaries of the national model and has dealt with larger and larger geographic areas and time periods. A wellknown and influential case is the Mediterranean history that Ferdinand Braudel delivers in his famous book on the subject (1972). During the past few decades, similar and diverse efforts of writing an Atlantic history from Columbus onwards have been tried by Elliott (2006), Lucena (2010), and Cañizares-Esguerra (2006), just to name a few, and more recently, by collective enterprises such as the Painting of the Kingdoms research project. Even bolder is the intellectual venture that David Christian (2011) is developing around the notion of 'big history', a history that starts with the Big Bang and is yet to be finished.
In all these cases, the traditional research methods of the humanities clash with the amount of information needed to make sense, select, and contextualize the events that will give shape to those histories. Key to all these efforts is the concept of flows of information, that is, the streams that continuously carry cultural information from one location to another, either through the movement of human beings, or through the movement of cultural items that at some point will be decoded and used in a different location from the place of creation. Flows of information respond to a general view of the way currents of culture cross borders, whether this cultural information is adopted by locals in its new destiny or not, as in the case of collections in modern museums. As opposed to cultural transfers, in which we assume an immediate interaction between local and exogenous agents, flows of information can take many forms and are telling about high and directed volumes of information.

As a last example in this introduction to a digital geography of Hispanic Baroque Art, we show how 
- Rubens, Pedro Pablo: $8.63 \%$

- Juárez, Luis: $7.11 \%$

- Zurbarán, Francisco de: $7.11 \%$

- Quispe Tito, Diego: 6.6\%

- López de Herrera, Alonso: $5.58 \%$

- Echave Orio, Baltasar de: $5.58 \%$

- Velázquez, Diego: $4.57 \%$

\section{Quispe Tito, Diego}

López de Herrera, Alonso

Juárez, Luis

\section{Rubens, Pedro Pablo}

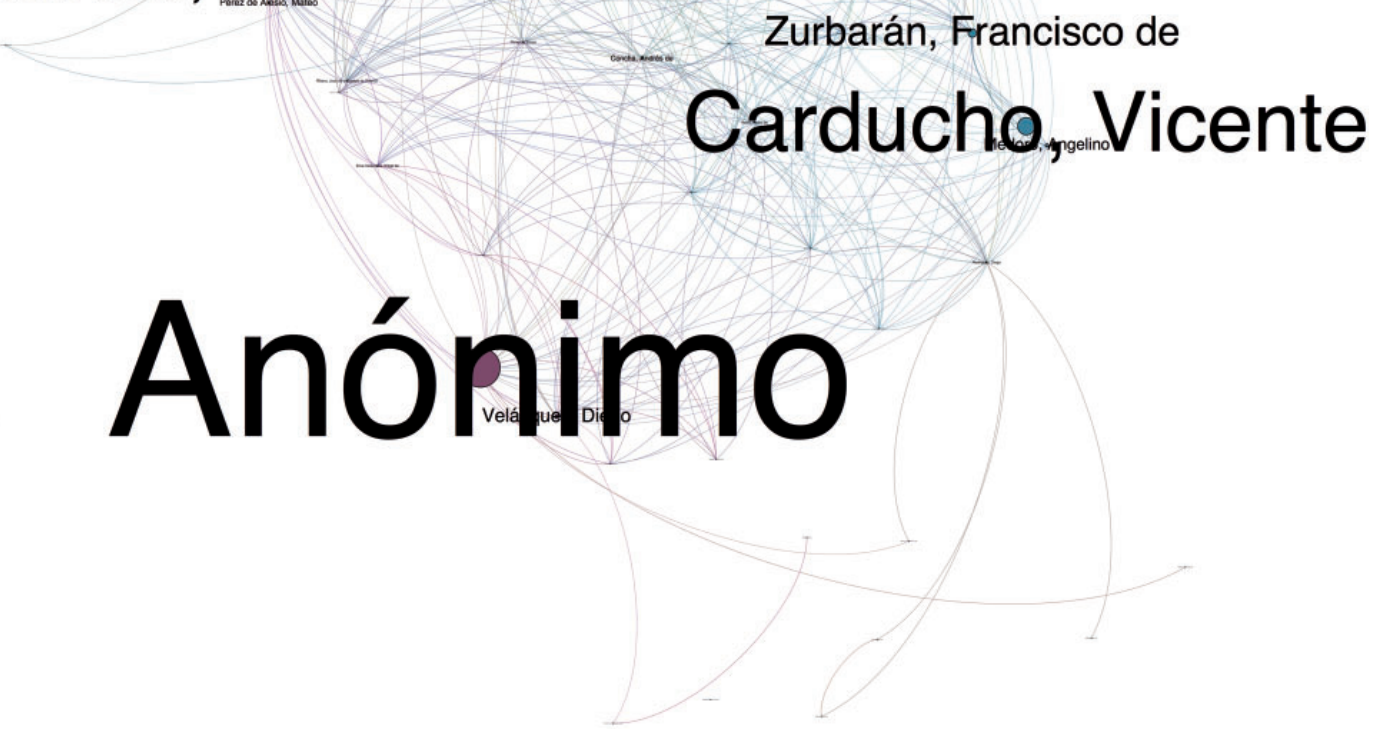

Fig. 9 Carducho, Rubens, and anonymous are most prominent in the period of 1550-1650.

current digital techniques allowed us to identify ongoing large flows of information and situate the cultural objects - the paintings - in contexts and histories different from those in which they originated. It is fair to say that these flows show how different the lived places of art can be from one period of human history to another. They also confirm that culture is an ever shape-changing organism that can serve different purposes in different cultural contexts, and that it is better studied through digital tools focusing on complex systems analysis.

We performed a query of our database taking into account the place of origin of the paintings (the first documented location when they were created or the original place for which they were commissioned), and also the current place in which they are held today, and then we visualized the results on a map, with the origin in red and the current location in green. The result is the map in Fig. 13, in which we have huge flows of artistic information taking place over time.

This visualization shows that most of the flows have happened from America (Mexico and Peru) to Europe and, to a lesser extent, to North America. In a few cases, the transfers have happened between Peru and Mexico, and more frequently, within regions of these countries. These flows can be 


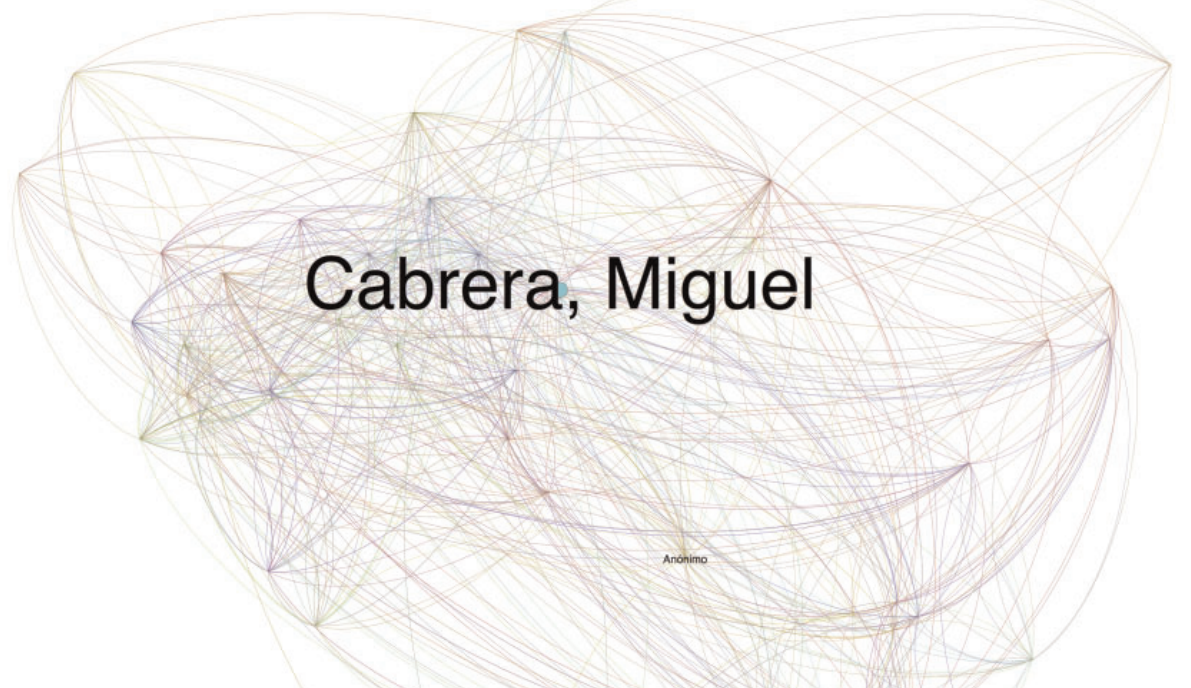

Percentage of artworks produced by artists in the period 1750-1850:

- Cabrera, Miguel: $30.98 \%$

- Anónimo: 18.55\%

- Goya y Lucientes, Francisco de: $8.91 \%$

- Islas, Andrés de: $4.08 \%$

- Páez, José de: $3.9 \%$

- Ibarra, José de: $3.71 \%$

Fig. 10 Cabrera's production is prominent over other artists' in the $1750-1850$ period.

interpreted in many different ways such as the one proposed by Báez (2009) or in colonial and postcolonial terms, and a variety of theories can be used to explain these economic and cultural phenomena. What interests us in this work is to show how the application of data analysis and visualization expose these flows and create another possible chapter in a digital geography of art. In this case, the flows call for the study of communities and cultural areas different from those we analyzed earlier in the article when talking about the historical Baroque period. These communities and areas respond to different criteria and are now related to the contemporary history of the museum, the global art market, or the postmodern geographies of a postcapitalist world. All of them connect to the various stories that can be told through a digital geography of Hispanic Baroque art.

\section{Conclusions: The Lived Spaces of the Hispanic Baroque}

We argue that the study of large-scale cultural systems such as the Hispanic Baroque is better tackled by a combination of tools and concepts that deal with the complex and evolving nature of the system, and can be studied through multi-scale techniques that reduce that complexity to a minimum, offering new ways of arranging the space in which that system unfolded over time.

A digital geography of art is a viable way of dealing with such complex systems of culture. A digital geography of art encompasses the various possible organizations of the place of art by digital means in a manner that relates different types of connected data about authors and artworks to different 
Percentage of artworks produced by artists

between 1650 - 1750:

- Anónimo: 14.98\%

- Martínez, Domingo: $12.62 \%$

- Correa, Juan (el Viejo): 9.31\%

- Villalpando, Cristóbal de: $4.26 \%$

- González, Miguel y Juan: 3.79\%

- Quispe Tito, Diego: 3.31\%

- Bocanegra, Pedro Atanasio: 3.15\%

- Rodríguez Juárez, Juan: $2.84 \%$

- Ibarra, José de: $2.84 \%$

- Martínez. Francisco: $2.84 \%$

- Torres, Antonio de: $2.68 \%, 57$

- Herrera, Fray Manuel de: $2.68 \%$

- Cabrera, Miguel: $2.52 \%$

- Salcedo, Juan Alonso de: $2.21 \%$

- Santa Cruz Pumacallao, Basilio de: $2.05 \%$

- Murillo, Bartolomé Esteban: 2.05\%

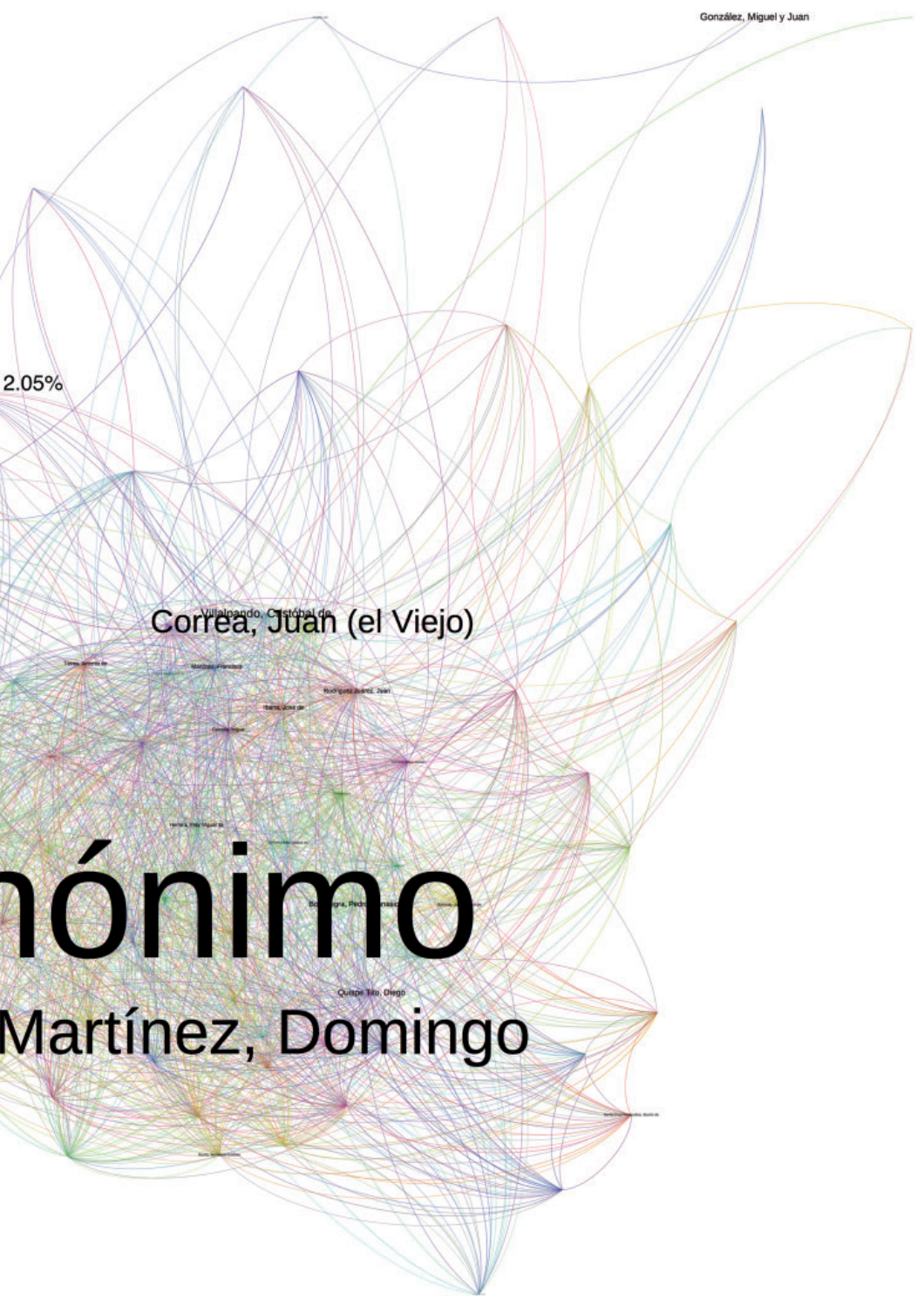

Fig. 11 The period (1650-1750) in which a larger variety of artists were exerting their influence at the same time.

notions of space, and to a variety of problems about human culture. The places of art become multiple in as much as they are considered in terms of what Soja called 'lived spaces' $(1996)^{9}$ of art, third spaces of cultural transitions that tell different stories about the human groups that have created, experienced, and lived through that art.
We have provided an initial list of elements of a digital geography of art: communities, areas, semantic maps, and flows. This list can be expanded or modified according to the data set, the findings in the data, and the interests of the researcher. The elements of a digital geography of art serve the methodological purpose of showing the multiple 


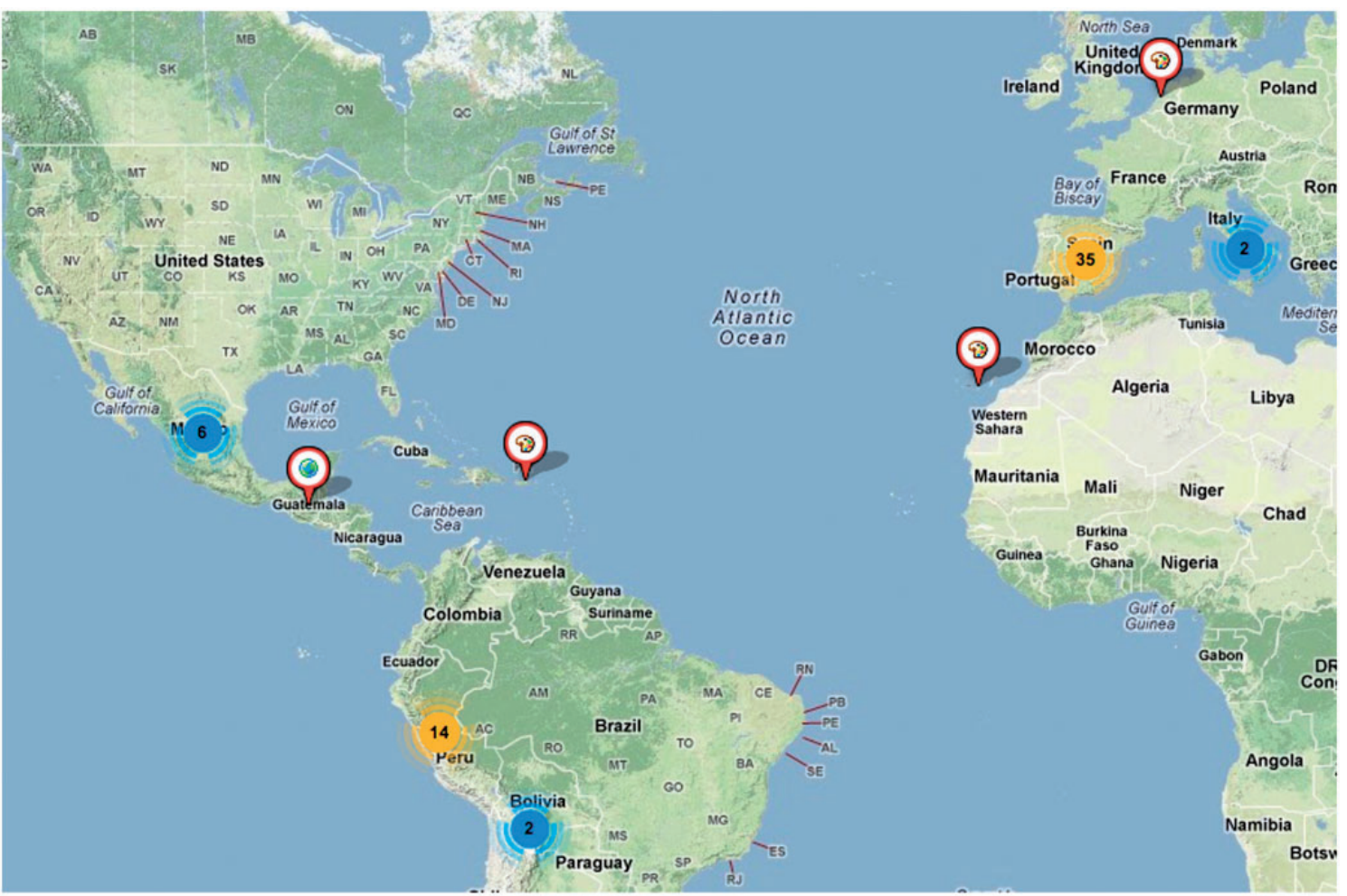

Fig. 12 Brown's Triptych of Hispanic Baroque Painting illustrating the flow of art across the Atlantic. Screenshot generated from the source tool baroqueart.cultureplex.ca.

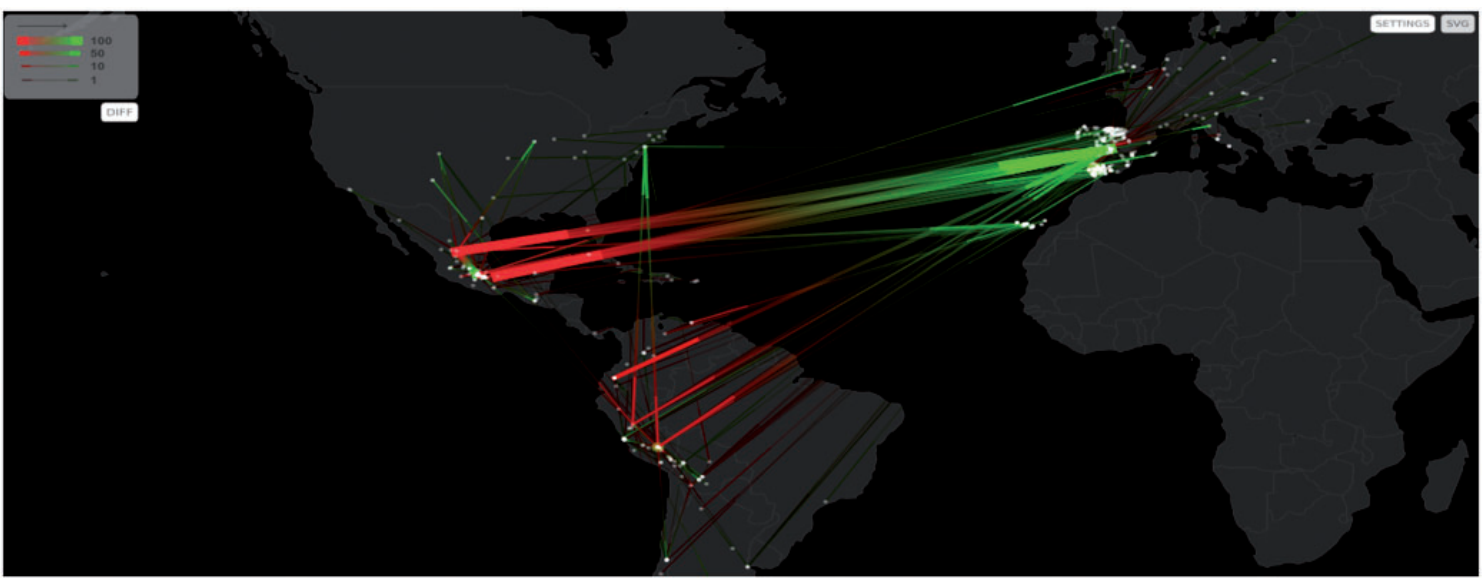

Fig. 13 Flow of artworks from their original production place (in red) to their current holding locations, mostly museums, galleries, and private collections (in green). 
power structures acting in a locality at a given time, how human groups activate cultural works in different contexts, that is, how the art space is lived in each case, and how cultural information forms a network that reflects the complexity of human life in the global age.

\section{Funding}

This work was supported by the Social Sciences and Humanities Research Council of Canada and the Canada Foundation for Innovation.

\section{References}

Báez, F. (2009). El Saqueo Cultural de América Latina: De la Conquista a la Globalización. Barcelona: Random House Mondadori.

BaroqueArt Database. (2010). Cultureplex, University of Western Ontario. http://baroqueart.cultureplex.ca/ (accessed 16 November 2012).

Boyd, R. and Richerson, P.J. (2005). Solving the Puzzle of Human Cooperation. In Levinson, S. (ed.), Evolution and Culture. Cambridge MA: MIT Press, pp. 105-132.

Braudel, F. (1972). The Mediterranean and the Mediterranean World in the Age of Philip II. New York: Harper and Row.

Brown, J. (1999). Los Siglos de Oro en los Virreinatos de América 1500-1700. In Catálogo de la exposición celebrada en el Museo de América entre el 23 noviembre de 1999 y el 12 de febrero de 2000. Madrid: Sociedad Estatal para la Conmemoración de los Centenarios de Felipe II y Carlos V.

Cañizares-Esguerra, J. (2006). Puritan Conquistadors: Iberianizing the Atlantic, 1550-1700. Stanford: Stanford University Press.

Castells, M. (2009). Communication Power. Oxford: Oxford University Press.

Christian, D. (2011). Maps of Time: An Introduction to Big History. Berkeley: University of California Press.

DaCosta Kaufmann, T. (2004). Toward a Geography of Art. Chicago: University of Chicago Press.

DaCosta Kaufmann, T. (2008). Pinturas de los reinos: A Global View of the Cultural Field. In Gutiérrez Haces, J. (ed.), Painting of the Kingdoms: Shared Identities: Territories of the Spanish Monarchy, vol. 1. México, D.F.: Fomento Cultural Banamex, pp. 86-136.
DaCosta Kauffman, T. (2010). Interpreting Cultural Transfer and the Consequences of Markets and Exchange: Reconsidering Fumi-e. In Artistic and Cultural Exchanges between Europe and Asia, 1400-1900. Burlington: Ashgate, pp. 134-161.

DiMaggio, P. (2011). Cultural Networks. In Scott, J. and Carrington, P.J. (eds), The SAGE Handbook of Social Network Analysis. Los Angeles: SAGE, pp. 286-300.

Elliott, J. H. (2006). Empires of the Atlantic World: Britain and Spain in America, 1492-1830. New Haven: Yale University Press.

Elliott, J. H. (2008). One King, Many Kingdoms. In Gutiérrez Haces, J. (ed.), Painting of the Kingdoms: Shared Identities: Territories of the Spanish Monarchy, 16th-18th Centuries, vol. 1. Mexico, D.F.: Fomento Cultural Banamex, pp. 40-83.

Goodenough, O.R. (2002). Information Replication in Culture: Three Modes for the Transmission of Culture Elements through Observed Action. In Nehaniv, C. L. and Dautenhahn, K. (eds), Imitation in Animals and Artifacts. Cambridge, MA: MIT Press, p. 573.

Gutiérrez Haces, J. (2008). Painting in New Spain as American Pictorial Koine? Progress in Ongoing Research. In Gutiérrez Haces, J. (coord.), Painting of the Kingdoms: Shared Identities: Territories of the Spanish Monarchy, 16th-18th Centuries, vol. 1. Mexico, D.F.: Fomento Cultural Banamex, pp. 136-185.

Flores Flores, O. and Fernández Flores, L. (2008). Pictorial Koineization in the Realms of the Spanish Monarchy. In Gutiérrez Haces, J. (ed.), Painting of the Kingdoms: Shared Identities: Territories of the Spanish Monarchy, 16th-18th Centuries, vol. 1. Mexico, D.F.: Fomento Cultural Banamex, pp. 186-335.

Heinrich, J. and Boyd, R. (2002). On Modeling Cognition and Culture. Journal of Cognition and Culture, 2(2): 87. http://www.swetswise.com/eAccess/ viewAbstract.do?articleID $=27381897 \&$ titleID $=111670$ (accessed 16 November, 2012).

Llewellyn, N. and Snodin, M. (eds), (2009). Baroque 1620-1800: Style in the Age of Magnificence. London: V\&A Publishing.

Lucena Geraldo, M. (2010). Naciones de Rebeldes: Las Revoluciones de Independencia Latino Americanas: A Los Cuatro Vientos: Las Cuidades de la America Hispanica. Madrid: Santillana Ediciones Generales, S.L.

McNeill, J. R. and McNeill, W. H. (2003). The Human Web: A Bird's Eye View of Human History. New York: Norton. 
Moretti, F. (2005). Graphs, Maps, Trees: Abstract Models for Literary History. New York: Verso.

Page, S. (2011). Diversity and Complexity. Princeton: Princeton University Press.

Richerson, P. J. and Boyd, R. (2006). Not By Genes Alone: How Culture Transformed Human Evolution. Chicago: University of Chicago Press.

Soja, E. (1996). Thirdspace: Journeys to Los Angeles and Other Real-and-Imagined Spaces. Cambridge: Blackwell.

Sperber, D. and Hirschfeld, L. (2004). The Cognitive Foundations of Cultural Stability and Diversity. Trends in Cognitive Science, 8(1): 40-46. http://re solver.scholarsportal.info/resolve/13646613/v08i0001/ 40_tcfocsad (accessed 16 November, 2012).

Suárez, J. L. and Olid-Peña, E. (2007). Hispanic Baroque: A Model for the Study of Cultural Complexity in the Atlantic World. South Atlantic Review, 72(1): 31-47. http://www.jstor.org/stable/27784678 (accessed 15 November 2012).

Suárez, J. L. and Sancho, F. (2011a). A Virtual Laboratory for the Study of History and Cultural Dynamics. Journal of Artificial Societies and Social Simulation, 14(4): 19. http://jasss.soc.surrey.ac.uk/14/ 4/19.html (accessed 16 November, 2012).

Suárez, J. L. and Sancho, F. (2011b). Toward a Descriptors Based Ontology of the Baroque System of Culture: General Concepts and Its Applications to the Classification of Painting. Submitted, Cultureplex, University of Western Ontario and Universidad de Sevilla.

Suárez, J. L., Sancho, F., and de la Rosa, J. (2011). The Art-Space of a Global Community: The Network of Baroque Paintings in Hispanic-America. 2011 Second International Conference on Culture and Computing, Kyoto, Japan, October 2011. http://cultureplex.ca/ media/publications/5.The_art_space_of_a_global_ community_the_network_of_Baroque_paintings_in_ Hispanic_America.pdf (accessed 16 November, 2012).

Suárez, J. L., Sancho, F., and de la Rosa, J. (2012). Sustaining a Global Community: Art and Religion in the Network of Baroque Hispanic-American Paintings. Leonardo, 45(3): 281. http://www.mitpressjournals.
org/doi/abs/10.1162/LEON_a_00374?journalCode= leon (accessed 16 November 2012).

Trudeau, R. J. (1993). Introduction to Graph Theory Corrected, enlarged republication ed. New York: Dover.

von Kügelen, Helga (2008). "Painting from the Kingdoms and Rubens". In Gutiérrez Haces, J. (ed.), Painting of the Kingdoms: Shared Identities: Territories of the Spanish Monarchy, 16th-18th Centuries, vol. 3. Mexico, D.F.: Fomento Cultural Banamex, pp. 1008-1078.

\section{Notes}

1 For a detailed explanation of the methodology, please refer to Juan Luis Suárez, Fernando Sancho, and Javier de la Rosa (2011b and 2012).

2 The four-volume catalogue Painting of the Kingdoms: Shared Identities were the result of the exhibition of the same name held from March 9 to Aug 31, 2011 at Palacio de Cultura Banamex, in Mexico City. Website: http://fomentoculturalbanamex.org/pinturadelosreinos/antecedentes.html

3 In the same catalogue, Óscar Flores Flores and Ligia Fernández Flores (2008) apply Gutiérrez Haces' koiné model to the various kingdoms of the Monarchy by exploiting the linguistic analogy and using the idea of identity along dialectal varieties.

4 See also the introductory chapter to his Toward a Geography of Art.

5 See also DaCosta Kauffman on cultural transfers Interpreting Cultural Transfer and the Consequences of Markets and Exchange (2010)

6 Rubens' work was present practically in all territories of Europe and America due to the spread of copies and engraving books.

7 See Scott Page (2011) on diversity and complexity.

8 See also bighistoryproject.com

9 For Soja, 'Spatiality [i.e. Socially produced space] is a substantiated and recognizable social product, part of a "second nature", [the transformed and socially concretized spatiality arising from the application of purposeful human labor] which incorporates as it socializes and transforms both physical and psychological spaces'. 